\title{
Superproof about Sexual Reproduction and Life Cycle in the Parasitic Generation of Strongyloides stercoralis in Human Host
}

\author{
Feleke Eriso \\ Department of Biology, Dilla University, Dilla, Ethiopia
}

Corresponding Author

Feleke Eriso

Mobile:

$+251916514682$

E mail: feleke.eriso@ yahoo.com

Key words: strongyloidiasis, morbi dity, mortality, infection, fulminant death
Background and study aim: Strongyloides stercoralis was believed to have two kinds of life cycles. One of them was an internal parthenogenetic life cycle that constituted the parasitic generation. Some authors also stated that this parasitic generation of the internal life cycle used to reproduce only by protandrogony (i.e., hermaphroditism). The second type of life cycle was the external sexual cycle, interacting among free-living worms that represented the free-living generation in soil. The key objectives of this study were to: verify the type of reproduction in the parasitic generation of $S$. stercoralis, and demonstrate the complete integrated life cycles of both parasitic and free-living generations of $S$. stercoralis.

Patients and Methods: The major sites of stool sample collection were selected to be the elementary schools (from students) at Dilla District, because S. stercoralis was ascertained to be endemic in this region. The parasitic worms of Strongyloides stercoralis obtained from fresh stools were used to set growth culture of free-living generation of this very species and to find the free-living

\section{INTRODUCTION}

Strongyloides (S). stercoralis is believed to have two kinds of life cycle: an internal parthenogenetic cycle that constitutes the parasitic generation, and the external sexual cycle, representing the free-living generation in soil [1-3]. It had been stated that the type of reproduction in the parasitic generation of $S$. stercoralis in human host was only by parthenogenesis of parasitic females in the absence of parasitic males [4-8]. Due to this concept of parthenogenesis the parasitic male had been omitted in the figures that demonstrated the life cycle of the parasitic generation of $S$. stercoralis in all modern and relevant textbooks, male and female in copulation from the growth culture. A set of parasitic male \& female in copulation isolated from a fresh stool sample of a patient under medical care in a hospital was also included.

Results: The male and female worms of S. stercoralis had been isolated from both parasitic and free-living generations while they were in the actual copulation.

Conclusion: The method of reproduction in the parasitic generation of S. stercoralis in human host was practically proved to be certainly sexual. This verified conclusion was the first practical achievement in the entire globe by solving the persistent problems (i.e., erroneous concepts of parthenogenesis and protandrogony as the types of reproduction in the parasitic generation of $S$. stercoralis) that had been misleading and puzzling the minds of the concerned scientists of the world until the establishment of this very achievement. Additionally, this achievement had enabled the investigator to construct the complete integrated life cycles of both parasitic and free-living generations of $S$. stercoralis.

journals, and on the internet. In the parasitic generation, when the filariform larvae are in contact with skin, they penetrate the small cutaneous blood vessels and are carried through the right heart to the lungs [9]. Then, the mature parasitic females settle in the tissues of epithelial mucosa to lay eggs that hatch soon and are discharged in stools each day $[\mathbf{1 0 , 1 1 ]}$. When all or some larvae metamorphose into infective filariform larvae autoinfection may be onset by invading the mucosa of the ileum or colon, travel to lungs and then return to the intestine to mature in the mucosa [12-15]. 
Disseminated strongyloidiasis had been reported in both of two recipients of kidney allografts from a single cadaver donor [16]. It was also reported that in a 53-year-old man who had lung cancer, fulminantly fatal strongyloidiasis had developed following postchemotherapy of immunosuppression, resulting in the death of the patient within 48 hours [16]. The development of a florid strongyloidiasis was observed in a 45-year-old man, following anticancer chemotherapy when eggs of S. stercoralis were seen in the stools [17]. One scientific study has reported that almost all deaths due to helminth in the United States result from $S$. stercoralis hyperinfection mortality rates because the occurrence of hyperinfection can be as high as $87 \%$ [18]. Concerning some morphological features of this parasite, the part of the worm's body that is known as the tail is the posterior part of body beginning from cloaca in the parasitic males or beginning from anus in the parasitic females. Cloaca is the opening through which spicules are everted at times of copulation and fertilization; and it is also the outlet of the digestive tract. The 3 stages of human strongyloidiasis are: Intestinal Strongyloidiasis, Gastropulmonary Strongyloidiasis, and Disseminated Strongyloidiasis [19-22]. Some of the clinical presentations (manifestations) of strongyloidiasis can be highlighted as: Cutaneous with larva currens (racing larvae), pruritic linear or serpiginous, creeping urticarial eruption, dermatologic lesions, and petechiae; Pulmonary with persistent wheezing, cough, and deteriorating respiratory status; and Intestinal with vomiting, abdominal pain, watery diarrhea and constipation.

\section{Aim of the study}

The aim of this study has two key objectives that are: to prove the fact that the type of reproduction in the parasitic generation of $S$. stercoralis is certainly sexual, and establish the complete integrated life cycles of both parasitic and free-living generations of $S$. stercoralis.

\section{PATIENTS AND METHODS}

The sites of collecting data were decided to be elementary schools at Dilla District, because S. stercoralis was ascertained to be endemic in this region. The purpose of collecting stools samples from different elementary schools was to set growth culture of free-living worms of $S$. stercoralis in sterilized topsoil from which the copulating free-living male $\left({ }^{\Uparrow}\right)$ and female $(+$ ) of this species can be isolated. Then, the form of copulation of this set of free-living male \& female was planned to be compared with that of parasitic male \& female isolated from a fresh stool sample taken from an HIV/AIDS patient under medical care in a hospital.

Sample Size. A total of 300 students were randomly examined for $S$. stercoralis. Those children with relatively large number of rhabditiform larvae of this parasite were used as the sources of stools samples for inoculating the worms into the sterilized topsoil in petridihes.

\section{Growth culture of free-living generation}

Topsoil that contained organic substance was taken and put into four different petridishes. Each of the petridishes was closed with its own lid and labeled 1,2,3 and 4; and then, the following 4 steps were implemented. The petridishes with their contents of topsoil were autoclaved.

The topsoil autoclaved in each of the petridishes was inoculated with fresh stool sample infected with $S$. stercoralis and identified to harbor relatively heavy worm-load of this parasite, before they had been given treatment.

Excess water was added to the topsoil of all the four petridishes and were incubated at $28{ }^{\circ} \mathrm{C}$ on the same day. With the aim to find the free-living male \& female in copulation, using a dropper a drop of soil suspension from each of the four topsoil petri dishes incubated was placed on a clean slide \& covered with a 22 square mm cover slip and examined under a compound light microscope everyday beginning from the 3rd day of incubation until the 5th day.

\section{Treatment}

The participant children who were found to be positive for S. stercoralis were given $400 \mathrm{mg}$ albendazole tablet to take with a glass of water on empty stomach in the morning and to begin taking meal at noon. This prescription \& clinical supervision was performed by a medical doctor (Dr.Corazon B. Jaca FMA).

\section{RESULTS}

On the 5th day from the date of setting the growth culture of free-living generation of $\mathrm{S}$. stercoralis, the free-living male \& female in copulation were found and isolated from the growth culture. The copulating pair was observed under a compound light microscope and microphotographed from the field of vision of the microscope using a digital camera. The 
copulating pair of the parasitic generation which was isolated from a fresh stool sample of an HIV/AIDS patient was microphotographed from the field of vision of the microscope in the same way with the digital camera. Now, the free-living male \& female in copulation, and the parasitic male \& female in copulation isolated from a fresh stool sample are spectacularly displayed for comparison.
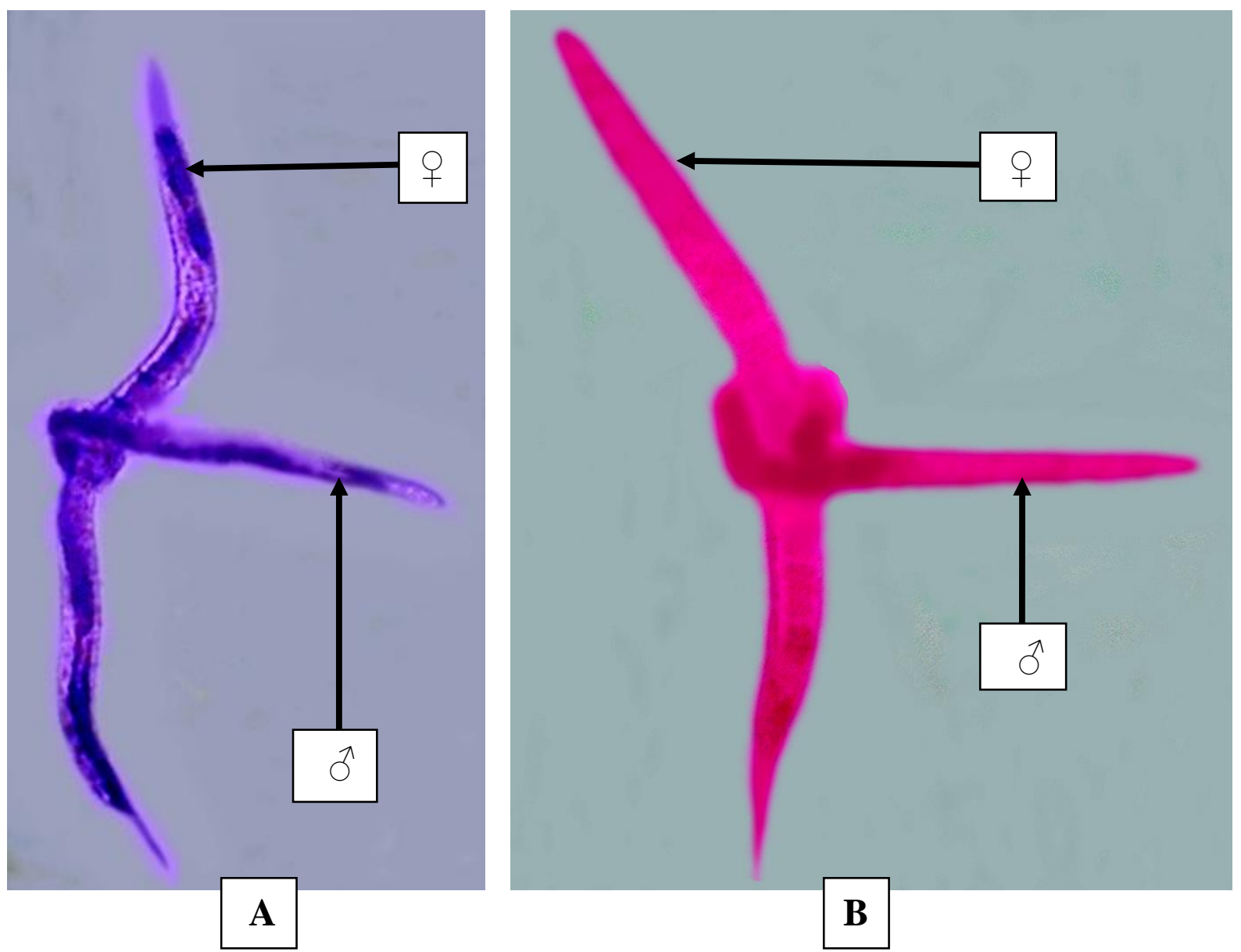

Figure (1): Copulation among the worms of Strongyloides stercoralis. Strongyloides stercoralis: (A), parasitic male $(\widehat{\jmath})$ \& parasitic female $(+)$ in copulation isolated from a fresh stool sample of an HIV/AIDS patient under medical care in a hospital \& microphotographed with a digital camera; and (B), free-living male $(\precsim) \&$ freeliving female $(q)$ in copulation isolated and then microphotographed with a digital camera from the growth culture of this very species by inoculating in an sterilized set of topsoil placed in a petridish and incubated at 28 ${ }^{\circ} \mathrm{C}$.

- The curved/coiled posterior body part of the male that coils around a specific body region of the female bears the genitals of the male everted at times of breeding (i.e., spicules everted out of spicule pouches found in cloaca).

- The specific body region of either parasitic or free-living female around which the curved/coiled posterior body part of the male coils bears vulva. The opening of vulva leads to a short muscular vagina which in turn leads to a pair of uteri of the adult female worm of S. stercoralis. 


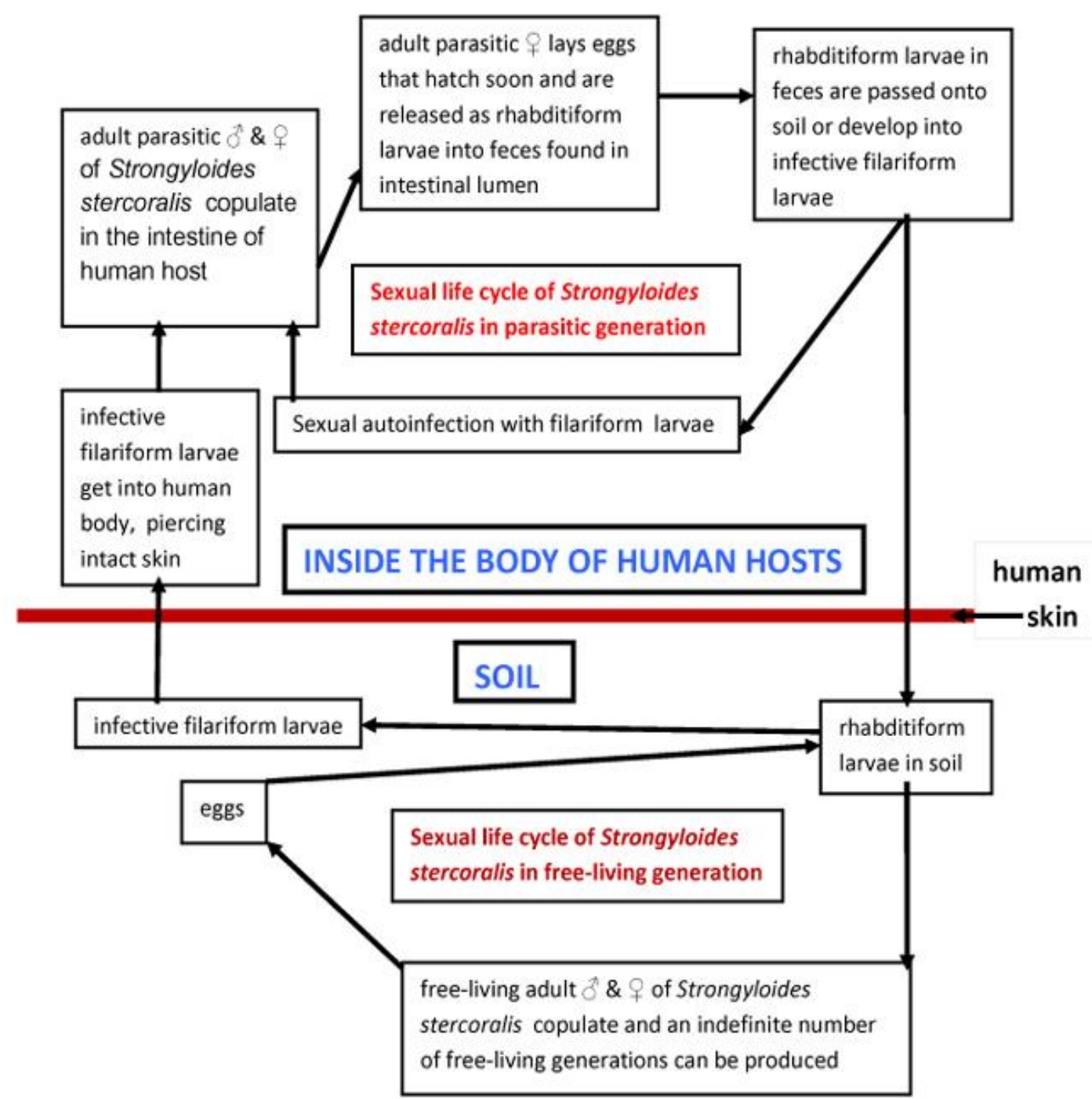

Figure (2): Complete integrated sexual life cycles of Strongyloides stercoralis in: parasitic generations in human host, and free-living generations in soil.

\section{DISCUSSION}

It has been believed that the type of reproduction of Strongyloides stercoralis in human host is parthenogenesis. In other words, parasitic males of $S$. stercoralis are never seen in human host until now. This is what has been written and reported: in modern textbooks of human/medical parasitology, in articles of famously reputable journals, on the internet, and from the minds of students of biology, and health sciences.

However, the presence of the parasitic males (just as there are parasitic females) of $S$. stercoralis in human host had been shown in a demonstrative practical study project executed by the researcher of this paper [23].
Authors of modern textbooks of the subject stated that parthenogenesis was the only method of reproduction; still some others had concluded that protandrogony (i.e., hermaphroditism) was the actual method of reproduction for $S$. stercoralis in human host [6]. Neither the belief of parthenogenesis nor that of protandrogony is acceptable/true as each of them does not have any scientific evidence or persuasive scientific background. Actually the presence of the parasitic males of S. stercoralis in human host had been reported and published in 2014, being enough to block the epidemic spread of erroneous concepts of parthenogenesis and protandrogony. Anyhow, the report of this paper is crucial at global level to irreversibly delete the misleading generalizations of parthenogenesis and protandrogony without 
delay: from modern textbooks of human/medical parasitology, from related articles of journals, from concerned sites of internet, and from the minds of students of biology, and health sciences.

It is because of this massive strength of eradicating/eliminating these erroneous concepts from the scientific discipline of the subject that the title of this paper begins with the word "Superproof". This is so because when the freeliving male $\&$ female copulate the curved/coiled

posterior body part of the male coils around a specific body region of the female in order to ejaculate (introduce) the male gametes into the female reproductive tract through the opening of vulva. As it has been seen in the copulation of free-living male and female, the same positional form of copulation is spectacularly observed in the copulating parasitic male \& female isolated from a fresh stool sample of a patient (Figure 1).

In conclusion, seeing the copulating of parasitic male and female of S. stercoralis with the observers' own eyes proved the fact that the method of reproduction of $S$. stercoralis was doubtlessly sexual. The usefulness of the integrated life cycles of the free-living \& parasitic generations has been kept in mind, because efficient preventive measures against parasitosis and devising effective treatment depend on understanding the biology \& life cycle of a parasite (which means understanding the nature of the disease).

\section{Conflict of interest}

I confirm that I don't have any competitive conflict of interest with anybody.

\section{Financial support}

The financial support to cover the cost of this study project was given by the Research \& Dissemination Office of Dilla University.

\section{Ethics}

Ethical permission/clearance to perform the research work to contribute to the well-being of human subjects was obtained from Dilla University, the Office of Gedeo-Zone Administration, and the Directors of Elementary Schools of Dilla District.

\section{Acknowledgements}

I am very much thankful to Dilla Ethiopian Catholic Church for its assigning a medical doctor (Dr. Corazon B. Jaca FMA) for prescription and clinical supervision in the process of treating the infected participant student children. I am also grateful indeed to Dilla University for its providing me with the necessary fund to cover the cost of this study project and writing the letters of cooperation or ethical permission to the Directors of Elementary Schools of Dilla District.

\section{REFERENCES}

1. Mitreva M, McCarter JP, Martin J, Dante M, Wylie $\mathrm{T}$, Chiapelli B, et al. Comparative genomics of gene expression in the parasitic and free-living nematodes Strongyloides stercoralis and Caenorhabditis elegans. Genome Res 2004 14(2):209

2. Concha R, Harrington WJR, Rogers AI. Intestinal strongyloidiasis: recognition, management, and determinants of outcome. J Clin Gastroenterol. 2005; 39: 203-11.

3. Hunter CJ, Petrosyan M, Asch M. Dissemination of Strongyloides stercoralis in a patient with systemic lupus erythematous after initiation of albendazole: a case report. J Med Case Reports 2008; 2: 156

4. Gilles HM. Soil-transmitted helminths (geohelminths). In: Cook GC.editor. Manson's Tropical diseases. 20th ed., London: WB Saunders ; 1996;1394-8, 1627.

5. Paniker CKJ. Textbook of medical parasitology. 6th ed., New Delhi; Jaypee Brothers Medical Publishers 2007; 169-74.

6. Bogitsh BJ, Carter CE, Oeltmann TN. Human parasitology. 3rd ed., USA; Academic press 2005; 334-9.

7. Dillard KJ, Saari SAM, Anttila M. Strongyloides stercorali infection in a Finnish kennel. Acta Vet Scand 2007; 49:37

8. Keiser PB, Nutman TB. Strongyloides stercoralis in the immunocompromised population. Clin Microbiol Rev 2004;17(1):208-17

9. Nolan TJ, Bhopale VM, Schad GA. Hyperinfective strongyloidiasis: Strongyloides stercoralis undergoes autoinfective burst in neonatal gerbils. J Parasitol 1999; 85: 286-9.

10. Dionisio D, Manneschi LL, Lollo SD, Orsi A, Tani A, Esperti F. Strongyloides stercoralis: ultrostructural study of newly hatched larvae within human duodenal mucosa. J Clin Pathol 2000; 53: 110-6.

11. Massey HCJ, Nishi M, Chaudhary K, Pakpout N, Lok JB. Structure and developmental expression of Strongyloides stercoralis. Int J Parasitol 2003; 33: 1537-44.

12. Garg PK, Perry S, Dorn M, Hardcastle L, Parsonnet J. Risk of intestinal helminth and protozoan infection in a refugee population. Am J Trop Med Hyg 2005; 83(3):4. 
13. Siddiqui AA, Berk SL. Diagnosis of Strongyloides stercoralis. Clin Infect Dis. 2001 ; 1;33(7):10407.

14.Siegel MO, Simon GL. Is human immunodeficiency virus infection a risk factor for Strongyloides stercoralis hyperinfection and dissemination? PLoS Negl Trop Dis 2012; 6(7): e1581

15.Ramanathan R, Nutman TB. Strongyloides stercoralis Infection in the Immunocompromised Host. Japan J Parasitol 2008; 10(2): 105-10.

16. Poonam P, Jayshree RS, Acharya RS, Hema S, Govind B, Suresh TM. Fulminant fatal Strongyloides stercoralis infection in a postchemotherapy immuno-suppressed cancer patient. Med Pediatric Oncol 1999; 33: 504-5.

17. Jayshree RS, Hema S, Govind B, Suresh TM. Strongyloides stercoralis eggs in the stools during anticancer therapy. Indian J Gastroenterol 2001; 20: 160-1.

18. Kim J, Joo HS, Ko HM, Na MS, Hw ASH, Im JC. A case of fatal hyperinfective strongyloidiasis with discovery of autoinfective filariform larvae in sputum. Korean J Parasitol 2005; 43: 51-5.

19. Fardet L, Genereau T, Poirot JL, Guidet B, Kettaneh A, Cabane L. Severe strongyloidiasis in corticosteroid-treated patients: case series and literature review. J Infect 2007; 54:18-27.
20. Kerepesi LA, Hess JA, Leon O, Nolan TJ, Schad GA, Abraham D. Toll-like receptor 4(TLR4) is required for protective immunity to larval Strongyloides stercoralis in mice. Microb Infect 2007; 9: 28-34.

21. Rahif RH, Emara GY, Al-saqur IM. Epidemiological study of intestinal nematodes in dogs in Basrah(Iraq): prevalence of helminthic ova in the fecal deposits. Iraqi J Vet Sci 2002; 16: 71-9.

22. Cheesbrough M. District laboratory practice in tropical countries. Part 1. India; Cambridge University Press 1998; 214-5.

23. Feleke E. Epidemiological studies on Strongyloides stercoralis at Dilla District, Ethiopia. AfroEgypt J Infect Endem Dis 2014; 4(2): 69-79.

Peer reviewers: Hala A El-Nahas, Professor of Medical Parasitology Faculty of Medicine, Mansoura University, Mansoura, Egypt; Ekhlas Hamed Abdel-Hafeez, Assistant Professor, Department of Parasitology, Faculty of Medicine, Minia University, Minia, Egypt. Maha Eissa, Professor of Medical Parasitology Faculty of Medicine, Alexandria University, Alexandria, Egypt

Editor: Mohamed H Emara; Lecturer of Tropical Medicine, Faculty of Medicine, Zagazig University, Egypt. 